Methods The group of 49 patients with SSc. (2 man and 47 woman) aged from 18 to 68 yrs (mean $48.16 \pm 15,8$ yrs) was investigated. Patient group with SSc comprised 13 patients with hypothyroidism and 36 patients with normal thyroid function. Nineteen volunteers ( 6 men and 13 women) were studied as a controls. Fasting serum total cholesterol, HDL and triglyceride levels as well as thyroid hormones were determined.

Results Increased cholesterol level was shown in patients with SSc. A significantly increased plasma triglyceride concentration and lower HDL level was found in hypothyroid SSc patients as compared to the SSc patients in euthyroid state. There was no differences in total cholesterol level between hypothyroid and euthyroid group of patients with SSC.

Conclusion

- There is no correlation between hypercholesterolemia and thyreometabolic state in patients with SSc

- Increased triglyceride level is secondary to impaired thyroid function in patients with SScc

\section{FRI0193 GASTRIC AND GALLBLADDER MOTILITY IN PATIENTS WITH SYSTEMIC SCLEROSIS: SIMULTANEOUS REAL-TIME ULTRASOUND STUDY}

'PJ Kotyla, 'EJ Kucharz, ${ }^{2}$ L Brzezinska-Wcislo, ${ }^{1}$ B Sliwinska-Kotyla. 'Department of Internal Medicine and Rheumatology; ${ }^{2}$ First Department of Dermatology, Medical University of Silesia, Katowioce, Poland

\subsection{6/annrheumdis-2001.274}

Background Progressive systemic sclerosis (SSc) is a connective tissue disease where fibrosis of skin and internal organ is a hallmark of disease activity. One of the most affected system in the patients is the alimentary tract.

Objectives The aim of the study was to determine self-related contraction and motor activity between stomach and gallbladder. Methods Study was performed in a group of twelve patients with SSc. Twelve sex- and age-matched healthy volunteers served as the controls. Gallbladder volume and emptying was assessed after ingestion of fat-rich $300 \mathrm{ml}$ semi-liquid fluid. Changing cross section antrum diameter was measured in the same time.

Results Delayed gastric emptying in patients with SSc was shown. Impaired gastric activity was especially seen in early and late phases of gastric emptying $(\mathrm{p} .<0,05)$ Gallbladder function was not altered, although compared to controls bile ejection fraction was slightly but statistically non-significant diminished.

Conclusion Gastric motility disturbances observed in patients with SSc are mainly due to its involvement in the course of disease. We postulate that slightly impaired gallbladder function did not augment gastric contraction impairment.

\section{FRI0194 CENTRAL NERVOUS SYSTEM INVOLVEMENT IN PATIENTS WITH SYSTEMIC SCLEROSIS: ELECTROENCEPHALOGRAPHIC STUDY}

PJ Kotyla, B Sliwinska-Kotyla, EJ Kucharz, L Brzezinska-Wcislo. Department of Internal Medicine and Rheumatology, Medical University of Silesia, Katowice, Poland

\subsection{6/annrheumdis-2001.275}

Background Central nervous system is rare affected in patients with systemic sclerosis. Subtle, very often non-specific symptoms and signs of the brain involvement in the patients were reported.
Objectives The present study was designed to detect and correlate electroencephalographic changes and to correlate them with the other neuro-psychiatric findings in patients with SSc.

Methods The study was performed in 12 SSc patients (11 women and $1 \mathrm{man})$. A routine 16-leads electroencephalograpic records were performed in the patients in morning hours after at least $8 \mathrm{~h}$ night rest. The patients underwent the following procedures during EEG examination: hyperpnea, intermittent photic stimulation (stroboscope light at $10 \mathrm{~min}$ at 10 to $30 \mathrm{~Hz}$ ) EEG alteration were classified on the base of following criteria: generalised slow activity $(4-6 \mathrm{~Hz})$, and presence of sharp waves, theta $(4-6 \mathrm{~Hz})$ delta $(2-3 \mathrm{~Hz})$. Focal alterations which fulfil the mentioned criteria were detected wit the special attention. In addition every patient underwent The routine neurologic examination was performed in every patients.

Results We recorded alpha rhythm of 9-11 Hz frequency and 20-100 uV amplitude as a basic rhythm in every patients. Nine patients showed no EEG abnormalities. In 5 patients we observed, especially in temporal regions presence of sharp waves induced mainly by hyperpnea. This group of patients presented symptoms of CNS involvement - mainly headaches, parasthesis, ataxia and some psychiatric abnormalities.

Conclusion In the course of SSc even subtle, non-specific symptoms may herald CNS involvement. EEG seems to be valuable method which confirm brain involvement in patients with SSc, presenting neurological and psychiatric abnormalities.

\section{FRI0195 PUPILLOCYNETIC ACTIVITY OF SUBSTANCE P IN SYSTEMIC SCLEROSIS (SSC)}

${ }^{1} \mathrm{~A}$ Del Rosso, 'L Bertinotti, ${ }^{2} \mathrm{M}$ Messori, 'U Pietrini, ${ }^{1} \mathrm{R}$ Sicuteri, ${ }^{1} \mathrm{~A}$ Messori, 'M Fanciullacci, ${ }^{1} \mathrm{M}$ Matucci Cerinic. 'Department Internal Medicine, Sect Rheumatology, Headache; ${ }^{2}$ Drugs Information Center, University of Florence, Florence, Italy

\subsection{6/annrheumdis-2001.276}

Background In SSc a dysfunction of peripheral nervous system (PNS) has been showed. SP instillation in human eye induces a cholinergic-independent pupil miosis via specific receptors on neuroirideal junction.

Objectives In order to study PNS function in SSc, we assessed by pupillometry pupil basal diameters and pupil ability to respond to SP instillation in SSc patients and in controls.

Methods 32 SSc patients [17 with limited (ISSc) and 15 with diffuse SSc (dSSc)] and 30 controls underwent pupillometry for evaluating basal iris diameters in both eyes. Then, SP was instilled in one eye [treated eye (TE)] and placebo in the other eye [not treated eye (NTE)] and the pupil response to SP instillation was assessed both in TE and in NTE. In order to verify the existence of a dose-dependence activity of SP, two different SP concentrations (10-3 and 10-5 M) were tested separately. For both eyes, t0 (pupil basal diameter) and AUC (iris pharmacological response to SP instillation) were considered. 2-tailed t-test was used to compare TE with NTE within groups and SSc with HC. ANOVA, Scheffè and Dunnett post-hoc tests were utilised to compare ISSc, dSSc and HC.

Results At $\mathrm{t} 0$, basal pupillary diameters of SSc resulted significantly minor in respect to HC $(\mathrm{p}<.001)$ and significant differences between 1SSc and dSSc and HC ( $p<.05)$, but not between $\mathrm{dSSc}$ and $\mathrm{HC}$, were found. Significant differences between SSc and controls were found in the response to SP 103 and 10-5, both for TE and for NTE ( $p<.05$ in all cases). The TE of ISSc showed a significant major miosis to SP 10-3 and $10-5$ instillation vs dSSc and controls $(\mathrm{p}<.05)$, whereas in 
the TE of dSSc pupillary miosis was not different from controls. In NTE, a significantly different miosis between $1 \mathrm{SSc}$ and controls was induced by both SP concentrations $(\mathrm{p}<.001)$, while a significant difference between 1SSc and dSSc was found only when SP 10-3 M was used ( $p=.002)$. In $\mathrm{dSS} c$, the instillation of SP 10-3, but not of SP 10-5 M, induced in NTE a more intense miosis in respect to controls NTE $(p=.004)$. The comparison between TE and NTE was significantly different in controls $(\mathrm{p}<.001)$, but not in 1SSc and in dSSc.

Conclusion Our results show that ISSc is characterised by the involvement of neuroirideal junction. In fact, the irideal basal diameter is reduced, and SP induces a more intense miosis in respect both to dSSc and to HC. The lack of difference between TE and NTE could be due to a dysfunction of peripheral nervous system, more likely involving central control mechanisms.

\section{FRI0196 RELATIONSHIP BETWEEN BRONCHOALVEOLAR LAVAGE (BAL) AND HIGH RESOLUTION-CT (HRCT) FINDINGS IN SCLERODERMA LUNG DISEASE}

${ }^{1} R$ La Corte, ${ }^{1} D$ Santilli, ${ }^{1} R$ Tieghi, ${ }^{1} A$ Lo Monaco, ${ }^{2} F$ Ravenna, ${ }^{3} R$ Galeotti, ${ }^{4} N$ Prandini, ${ }^{1} \mathrm{~F}$ Trotta. ${ }^{1}$ Sez. Di Reumatologia; ${ }^{2}$ Ist. Di Pneumologia; ${ }^{3}$ st. Di Radiologia; ${ }^{4}$ Serv. Di Med. Nucleare, Università Di Ferrara, Ferrara, Italy

10.1136/annrheumdis-2001.277

\section{Background}

Objectives We assessed the presence of alveolitis by means of BAL and its correlations with HRCT findings in the diagnosis of systemic sclerosis (SSc)-related interstitial lung disease (SSc-ILD). Methods 43 nonsmoking patients (pts) with SSc, with a mean age of $54.62 \pm 2.08$ years (range $23-74$ ), underwent to: bronchoscopy with BAL according to the 1990 American Thoracic Society guidelines; ${ }^{1}$ lung HRCT, graded according to a scoring system proposed by Warrick et al.; ${ }^{2}$ and SSc-related antibodies testing.

Results Patients with alveolitis (A) and those without alveolitis (NA), divided according to BAL results, were comparable as to mean age and duration of disease, to the prevalence of diffuse or limited subset of disease, to mean values of skin score and to the results of examinations with respiratory function tests, diffusing capacity for carbon monoxide, and inhaled 99mTc-DTPA for the measure of alveolar clearance rate performed as part of the whole clinical assessment. BAL showed the presence of alveolitis in $18 / 43$ pts $(41.8 \%)$ with cell profiles so distributed: lymphocytic (L) in $5 / 18$ pts $(27.7 \%)$; eosinophilic (E) in 1/18 (5.5\%); pure neutrophilic $(\mathrm{N})$ in $5 / 18(27.7 \%)$ and a mixed pattern $(3 \mathrm{~N}$ $+\mathrm{L}, 3 \mathrm{~N}+\mathrm{E}, 1 \mathrm{~N}+\mathrm{L}+\mathrm{E})$ in $7 / 18(38.8 \%)$. Both "total HRCT" score $(14.3 \pm 1.2$ vs $9.2 \pm 1.2 ; \mathrm{p}=0.01)$ and "severity of disease" score $(8.8 \pm 0.8$ vs $6.0 \pm 0.8 ; \mathrm{p}=0.02)$ yelded significantly higher values in A pts compared with NA pts. Among HRCT abnormalities, only "honeycombing" (HC) was significantly more frequent in A pts $(\mathrm{p}=0.033)$; while the presence of "ground glass" (GG), "irregular pleural margins", "septal/subpleural lines" and "subpleural cysts" showed no differences between A and NA pts. Anti Scl-70 positivity was more prevalent in A pts $(\mathrm{p}=0.015)$ and, whether or not alveolitis was present, it correlated with higher "total HRCT" scores ( $\mathrm{p}=$ 0.039).

Conclusion Seemingly, GG cannot be unambiguously considered as the radiographic sign of alveolitis, since the latter is more prevalent in patients with $\mathrm{HC}$ which so, far from being the equivalent of a purely fibrotic outcome, could represent pathologic lung tissue that still retains some ongoing and potentially treatable inflammatory activity. Moreover, we confirm the role of anti Scl-70 as a negative prognostic marker associated with SSc-ILD.

\section{REFERENCES}

1 Am Rev Respir Dis. 1990;142:481

2 J Rheumatol. 1991;18:1520

\section{FRI0197 PROSTAGLANDIN E1 INFUSIONS AND PLASMA HOMOCYSTEINE IN SYSTEMIC SCLEROSIS}

${ }^{1} \mathrm{M}$ Massarotti, ${ }^{2} \mathrm{C}$ Maioli, ${ }^{2} \mathrm{~A}$ Bestetti, ${ }^{3} \mathrm{R}$ Coppola, ${ }^{4} \mathrm{~S}$ Leviti, ${ }^{1} \mathrm{~B}$ Marasini. ${ }^{1}$ Department of Medicine, Surgery and Dentistry, University of Milan; ${ }^{2}$ Institute of Radiological Sciences; ${ }^{3}$ Angelo Bianchi Bonomi Haemophilia and Thrombosis Centre, IRCCS Maggiore Hospital, Milan, Italy; ${ }^{4}$ Clinical Chemistry Laboratory

\subsection{6/annrheumdis-2001.278}

Background Although elevated plasma levels of homocysteine (Hcy) are considered a risk factor for vascular events, it is still uncertain if the lowering of Hcy by folate restores endothelial function.

Objectives We evaluated the relationship between Hcy and endothelial damage in systemic sclerosis (SSc), measuring plasma levels of von Willebrand factor ( $\mathrm{vWf}$ ), a well accepted marker of endothelial dysfunction, and Hcy, after treatment with PGE1, which has no known interferences with Hcy metabolism and whose long-term benefit is thought to be due to improvement of endothelial function.

Methods Sixty mcg PGE1 (alprostadil alpha-cyclodextrine) in $250 \mathrm{ml} 0.9 \%$ saline daily were infused daily for a 5 days-period (1st cycle), and after 1 and 2 months for 1 day-period thereafter (2nd and $3 \mathrm{rd}$ cycle, respectively) to $10 \mathrm{SSc}$ patients (2 with the diffuse, dSSc, 7 with the limited type, ISSc, 1 with SSc sine scleroderma. Hcy (immunoassay), vWf (ELISA) and folic acid (radioassay) were measured before each cycle.

Results Hcy was reduced vs baseline before the 2nd and 3rd cycle $(11.30 \pm 3.23$ and $12.16 \pm 4.86$ vs $14.46 \pm 5.31 \mathrm{mcM} / \mathrm{L}$, $\mathrm{p}<0.005$ and $\mathrm{p}=0.0616$, respectively; mean $\pm \mathrm{SD}$ ), with a percent decrease vs baseline significantly greater in dSSc vs $1 S S c$ $(66.0 \pm 9.7$ vs $83.1 \pm 7.0 \%, p<0.03$ and $64.2 \pm 14.5$ vs 88.4 $\pm 6.0 \%, \mathrm{p}<0.05,2 \mathrm{nd}$ and $3 \mathrm{rd}$ cycles). vWf was also reduced $(167 \pm 39$ and $156 \pm 27$ vs $183 \pm 12 \mathrm{U} / \mathrm{dl}, \mathrm{p}<0.05)$, with no differences between $1 S S c$ or dSSc. Folic acid did not change $(4.68 \pm 1.56,4.94 \pm 2.09$ and $4.54 \pm 1.71 \mathrm{ng} / \mathrm{ml})$. No relationship was observed between Hcy and vWf.

Conclusion These data are consistent with Hcy as a marker rather than a risk for endothelial damage. Further studies are however needed to evaluate the relatioship of Hcy and vWf plasma levels with endothelial function.

\section{FRI0198 THE ULTRASTRUCTURE OF THE MUSCLE COAT OF THE GASTRIC WALL IN A CASE OF SYSTEMIC SCLEROSIS (SSC)}

${ }^{1} \mathrm{~L}$ Ibba Manneschi, ${ }^{2} \mathrm{~A}$ Del Rosso, ${ }^{1} \mathrm{~A}$ Tani, ${ }^{1} \mathrm{~S}$ Pacini, ${ }^{3} \mathrm{P}$ Bechi, ${ }^{2} \mathrm{M}$ Matucci Cerinic. ${ }^{1}$ Department Anatomy, Histology and Forensic Medicine; ${ }^{2}$ Department Internal Medicine, Sect Rheumatol; ${ }^{3}$ Clinical Surgery, University of Florence, Florence, Italy

10.1136/annrheumdis-2001.279

Background In Systemic Sclerosis (SSc) the gastrointestinal (GI) involvement leads to hypomotility and dysphagia at esophageal 